\title{
A grid-based model of backwasting of supraglacial ice cliffs on debris-covered glaciers
}

\author{
Pascal BURI, ${ }^{1}$ Francesca PELLICCIOTTII, ${ }^{1,2}$ Jakob F. STEINER, ${ }^{1}$ Evan S. MILES, ${ }^{3}$ \\ Walter W. IMMERZEEL ${ }^{4}$ \\ ${ }^{1}$ Institute of Environmental Engineering, ETH Zürich, Zürich, Switzerland \\ ${ }^{2}$ Department of Geography, Northumbria University, Newcastle upon Tyne, UK \\ ${ }^{3}$ Scott Polar Research Institute, University of Cambridge, Cambridge, UK \\ ${ }^{4}$ Department of Physical Geography, Utrecht University, Utrecht, Netherlands \\ Correspondence: Pascal Buri <buri@ifu.baug.ethz.ch>
}

\begin{abstract}
Ice cliffs might be partly responsible for the high mass losses of debris-covered glaciers in the Hindu Kush-Karakoram-Himalaya region. The few existing models of cliff backwasting are pointscale models applied at few locations or assume cliffs to be planes with constant slope and aspect, a major simplification given the complex surfaces of most cliffs. We develop the first grid-based model of cliff backwasting for two cliffs on debris-covered Lirung Glacier, Nepal. The model includes an improved representation of shortwave and longwave radiation, and their interplay with the glacier topography. Shortwave radiation varies considerably across the two cliffs, mostly due to direct radiation. Diffuse radiation is the major shortwave component, as the direct component is strongly reduced by the cliffs' aspect and slope through self-shading. Incoming longwave radiation is higher than the total incoming shortwave flux, due to radiation emitted by the surrounding terrain, which is $25 \%$ of the incoming flux. Melt is highly variable in space, suggesting that simple models provide inaccurate estimates of total melt volumes. Although only representing $0.09 \%$ of the glacier tongue area, the total melt at the two cliffs over the measurement period is 2313 and $8282 \mathrm{~m}^{3}, 1.23 \%$ of the total melt simulated by a glacio-hydrological model for the glacier's tongue.
\end{abstract}

KEYWORDS: debris-covered glaciers, energy balance, glacier mass balance, mountain glaciers, surface melt

\section{INTRODUCTION}

Debris-covered glaciers are common in many mountain ranges of the world, and in the Hindu Kush-KarakoramHimalaya $(\mathrm{HKH})$ region in particular (e.g. Bolch and others, 2012), but they are rarely studied and poorly understood. Several works have focused on understanding the energy transfer through debris and the melt of the ice underneath. With few exceptions (Reid and others, 2012; Fujita and Sakai, 2014; Fyffe and others, 2014), however, most have been limited to analysis at the point scale, ignoring the complex and dynamic surfaces of many debris-covered glaciers (Benn and others, 2012; Pellicciotti and others, 2015). A number of recent studies based on remote sensing have suggested that, despite the reduction in melt caused by debris thicker than a few centimetres, as observed in experiments at single points, debris-covered glaciers in the $\mathrm{HKH}$ region are losing mass at rates similar to those of debris-free glaciers (Gardelle and others, 2012, 2013; Kääb and others, 2012; Nuimura and others, 2012). This discrepancy has been referred to as the debris-cover anomaly (Pellicciotti and others, 2015). The findings have been obtained only for a very recent period, and are controversial (Kääb and others, 2012), but have prompted research on possible causes of such high rates of mass loss from debris-covered ice. Some authors have suggested that these might be due to the presence of supraglacial lakes and cliffs that offer surfaces where high melt rates can occur (Sakai and others, 1998; Benn and others, 2012;
Pellicciotti and others, 2015). These features are commonly observed at low elevations on semi-stagnant tongues covered in thick debris (Benn and others, 2012; Pellicciotti and others, 2015), but there are relatively few quantitative studies of ablation at ice cliffs (Sakai and others, 1998, 2002; Han and others, 2010; Reid and Brock, 2014; Steiner and others, 2015), and all are limited to point models of backwasting. Han and others (2010) calculated backwasting for 38 cliffs on Koxkar glacier, Tien Shan, China, but regarded each cliff as a plane with constant slope and aspect and applied a point calculation to each of them. Their model was modified by Reid and Brock (2014), who included a term to account for the effect of longwave radiation originating from close-range local topography. Debris mounds near the ice cliffs emit longwave radiation that can be intense, because of the high temperatures debris can reach during the day (up to $30-40^{\circ} \mathrm{C}$; Steiner and others, 2015). It has been proposed that this effect, in combination with reduced shortwave radiation, is responsible for the survival of inclined poleward-facing cliffs (Sakai and others, 2002). Reid and Brock (2014) accounted for the longwave radiation emitted by debris using an empirical debris-view factor above the horizontal, which they obtained through calibration. They used the model to calculate ablation at a number of stakes at five cliffs on Miage glacier, Italy, that were monitored in two years, and then extrapolated the results to the glacier scale by running the model on every cell of cliff surfaces 


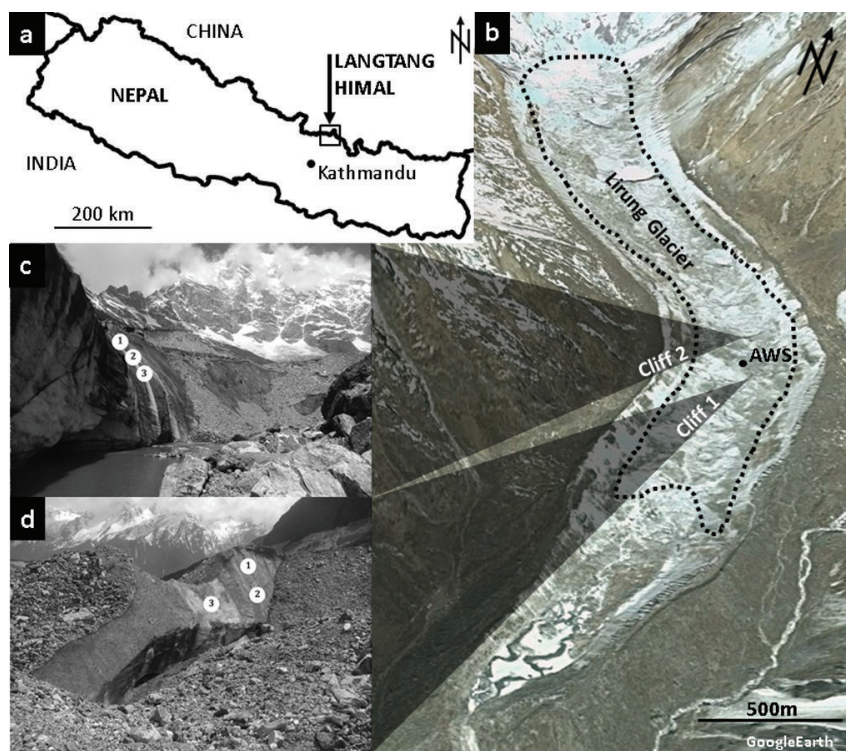

Fig. 1. (a) Overview of Langtang region. (b) The tongue of Lirung Glacier as it appears on Google Earth. (c, d) The two investigated cliffs, cliff 2 (c) and cliff 1 (d). The on-glacier automatic weather station (AWS) (called AWS Lirung in this paper) is marked with a black dot. The approximate extent of the debris-covered tongue is shown with a dashed curve. The stake locations on the cliffs in May 2013 are indicated with white dots and their corresponding number in (c) and (d).

identified from a high-resolution digital elevation model (DEM). Steiner and others (2015) replaced the empirically determined debris-view factor with a calculation of the debris- and sky-view factors based on geometric considerations, a radiation model and an accurate DEM $(0.2 \mathrm{~m}$ resolution) of the glacier.

No previous gridded model of cliff backwasting exists, and previous distributed estimates have all been obtained from extrapolation of point measurements, running multiple point runs (Reid and Brock, 2014) or assuming that the cliff is a plane with constant geometry, slope and aspect (Sakai and others, 1998; Han and others, 2010). In this paper, we build on the point model developed by Steiner and others (2015), to develop a distributed model of cliff backwasting, in which the cliff is represented as a gridbased domain of cells of $0.2 \mathrm{~m}$ resolution. In this way, the real, complex geometry of the cliff can be taken into account in the calculation of energy fluxes and ablation rates. Our aims are (1) to understand the spatial patterns of radiative fluxes and melt over two cliffs on one debriscovered glacier and (2) to accurately quantify (and not by extrapolation) the total mass lost by the two cliffs during one ablation season.

We use data collected at two cliffs on the debris-covered tongue of Lirung Glacier in one melt season, May-October 2013. The data include meteorological observations, measurements of melt at the cliffs (perpendicular to the surface), observations of cliff geometry and a $0.2 \mathrm{~m}$ DEM derived from repeated flights with an unmanned aerial vehicle (UAV) equipped with a camera. The data have been used by Steiner and others (2015), who describe them in detail. We recall the main characteristics of the dataset, then describe the model and the shortwave and longwave calculations in particular, and discuss the results at the two study cliffs, which differ in size and shape.
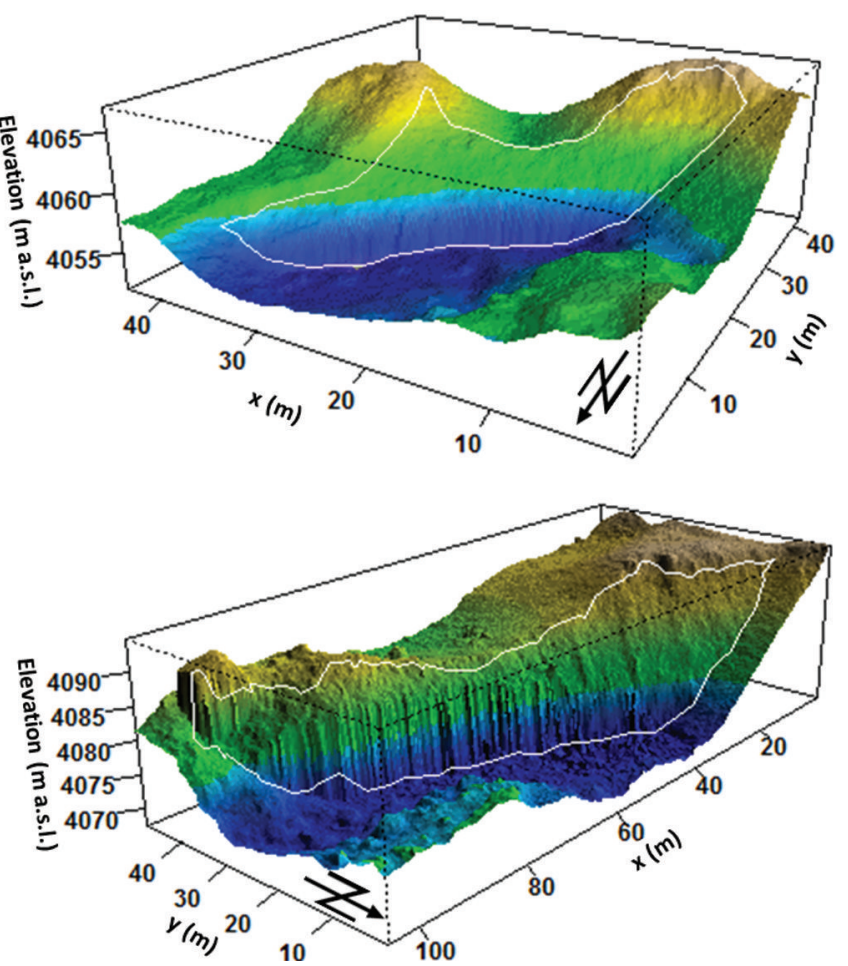

Fig. 2. Three-dimensional view of cliff 1 (top) and cliff 2 (bottom) based on the UAV-DEM from May 2013, looking from northwest (cliff 1 ) and northeast (cliff 2) and coloured according to elevation. A colour scale is not shown, as the elevation scale is provided by the $z$-axis. The borders of the cliff areas are indicated with white curves.

\section{STUDY SITE}

Debris-covered Lirung Glacier $\left(28.2325^{\circ} \mathrm{N}, 85.5619^{\circ} \mathrm{E}\right)$ is located in the Upper Langtang Valley, Central Nepalese Himalaya (Fig. 1). The Langtang catchment has an area of $350 \mathrm{~km}^{2}$ and contains 72 glaciers (Shiraiwa and Yamada, 1992) which cover $118 \mathrm{~km}^{2} \quad(\sim 1 / 3$ of the total area) (Shiraiwa and Yamada, 1992; Ragettli and others, 2015). The largest glaciers have debris-covered ablation zones, and $24 \%$ of the glacierized area is covered by debris (Pellicciotti and others, 2015). Lirung Glacier has an elevation range of $\sim 4004-7234 \mathrm{~m}$ a.s.l., and its tongue, which is decoupled from the steep accumulation zone above, is in the range $\sim 4000-4450 \mathrm{~m}$ a.s.l. and measures $3.5 \mathrm{~km}$ in length and $500 \mathrm{~m}$ in width (Immerzeel and others, 2014). The debris is heterogeneous, ranging in size from large boulders to finer sediments, and is $>50 \mathrm{~cm}$ thick for most of the tongue (Ragettli and others, 2015).

Supraglacial cliffs and lakes are common on the glacier tongue (Sakai and others, 1998, 2000; Immerzeel and others, 2014; Steiner and others, 2015; Miles and others, 2016). In 2013, a total of 13 supraglacial ice cliffs were observed on the glacier tongue, including eight in the UAV survey area. In this paper we focus on two cliffs that were monitored in detail in May and October 2013 during extensive field campaigns. The aim of the field campaigns was to provide the data for a modelling effort to understand the response of the debris-covered glaciers of the valley to a changing climate (Ragettli and others, 2015). The smaller cliff, cliff 1 (10 m high, $45 \mathrm{~m}$ long), has a northwesterly aspect, while cliff 2 (25 m high, $95 \mathrm{~m}$ long) mainly faces northeast (Fig. 2; Table 1). 
Table 1. Characteristics of the two supraglacial ice cliffs on Lirung Glacier investigated in this study: mean, standard deviation (SD), minimum and maximum value (min. and max., respectively) and coefficient of variation ( $C V=S D / m e a n)$. Elevation is in $m$ a.s.l. (and $\mathrm{m}$ for SD), slope and aspect are in degrees (with $0 / 360^{\circ}$ indicating northern and $180^{\circ}$ indicating southern directions). $V_{\mathrm{s}, \mathrm{l}}$ and $V_{\mathrm{s}, \mathrm{L}}$ are the sky-view factors for shortwave radiation and longwave radiation, respectively; $V_{d}$ is the debris-view factor. The three viewing factors are dimensionless. The values for the AWS are shown at the bottom for comparison

\begin{tabular}{|c|c|c|c|c|c|c|}
\hline & Variable & Mean & SD & Min. & Max. & $\mathrm{CV}$ \\
\hline \multirow{6}{*}{ Cliff 1} & Elevation & 4058 & 3.10 & 4052 & 4066 & 0.00 \\
\hline & Slope & 45.60 & 13.77 & 0.37 & 83.10 & 0.30 \\
\hline & Aspect & 327.70 & 29.49 & & & \\
\hline & $V_{\mathrm{s}, \mathrm{I}}$ & 0.63 & 0.05 & 0.47 & 0.73 & 0.08 \\
\hline & $V_{\mathrm{s}, \mathrm{L}}$ & 0.75 & 0.07 & 0.53 & 0.93 & 0.37 \\
\hline & $V_{\mathrm{d}}$ & 0.23 & 0.09 & 0.11 & 0.54 & 0.37 \\
\hline \multirow[t]{6}{*}{ Cliff 2} & Elevation & 4081 & 5.55 & 4068 & 4093 & 0.00 \\
\hline & Slope & 53.23 & 15.13 & 2.23 & 86.66 & 0.28 \\
\hline & Aspect & 29.37 & 27.12 & & & \\
\hline & $V_{\mathrm{s}, \mathrm{I}}$ & 0.59 & 0.07 & 0.37 & 0.73 & 0.11 \\
\hline & $V_{s, L}$ & 0.72 & 0.09 & 0.40 & 0.93 & 0.49 \\
\hline & $V_{\mathrm{d}}$ & 0.21 & 0.09 & 0.08 & 0.55 & 0.41 \\
\hline \multirow[t]{6}{*}{ AWS Lirung } & Elevation & 4062 & & & & \\
\hline & Slope & 9.18 & & & & \\
\hline & Aspect & 25.53 & & & & \\
\hline & $V_{\mathrm{s}, \mathrm{I}}$ & 0.70 & & & & \\
\hline & $V_{\mathrm{s}, \mathrm{L}}$ & 0.83 & & & & \\
\hline & $V_{\mathrm{d}}$ & 0.17 & & & & \\
\hline
\end{tabular}

\section{DATA}

\subsection{Meteorological data}

Meteorological data were recorded at 5 min intervals at an automatic weather station (AWS Lirung, 4076 ma.s.I.) located on the tongue of Lirung Glacier (Fig. 1). The station was installed between the two cliffs in spring 2013 and recorded until autumn 2013 (from 8 May to 23 October 2013). The measurement period was divided into three subseasons (following Immerzeel and others, 2014): (1) 'premonsoon' (8 May-14 June), (2) 'monsoon' (15 June19 September) and (3) 'post-monsoon' (20 September23 October).

The station recorded the following meteorological variables used for the modelling: air temperature (shielded and ventilated), $T_{\mathrm{a}}\left({ }^{\circ} \mathrm{C}\right)$, incoming shortwave radiation (parallel to the gently sloped surface), $I_{\text {in }}\left(\mathrm{W} \mathrm{m}^{-2}\right)$, relative humidity of the air, $h_{\mathrm{r}, \mathrm{a}}(\%)$, and wind speed, $u\left(\mathrm{~m} \mathrm{~s}^{-1}\right)$, all measured at $2 \mathrm{~m}$ above ground. The sensor set-up and specifications are described by Steiner and others (2015). Debris surface temperature, $T_{\mathrm{s}}\left({ }^{\circ} \mathrm{C}\right)$, was measured with a temperature logger HOBO TidbiT v2 (UTBI-001) wrapped in reflecting tape and placed on a rock near the station (see Petersen and Pellicciotti, 2011, for details of the sensor). Incoming longwave radiation, $L_{\text {in }}\left(\mathrm{W} \mathrm{m}^{-2}\right)$, was not measured and is therefore modelled (see Section 4.3).

\subsection{Topographic data}

In both May and October 2013 a UAV collected photographs which were processed to generate two highresolution DEMs $(0.2 \mathrm{~m})$ for May and October (Immerzeel and others, 2014). The two UAV-DEMs cover the lower part
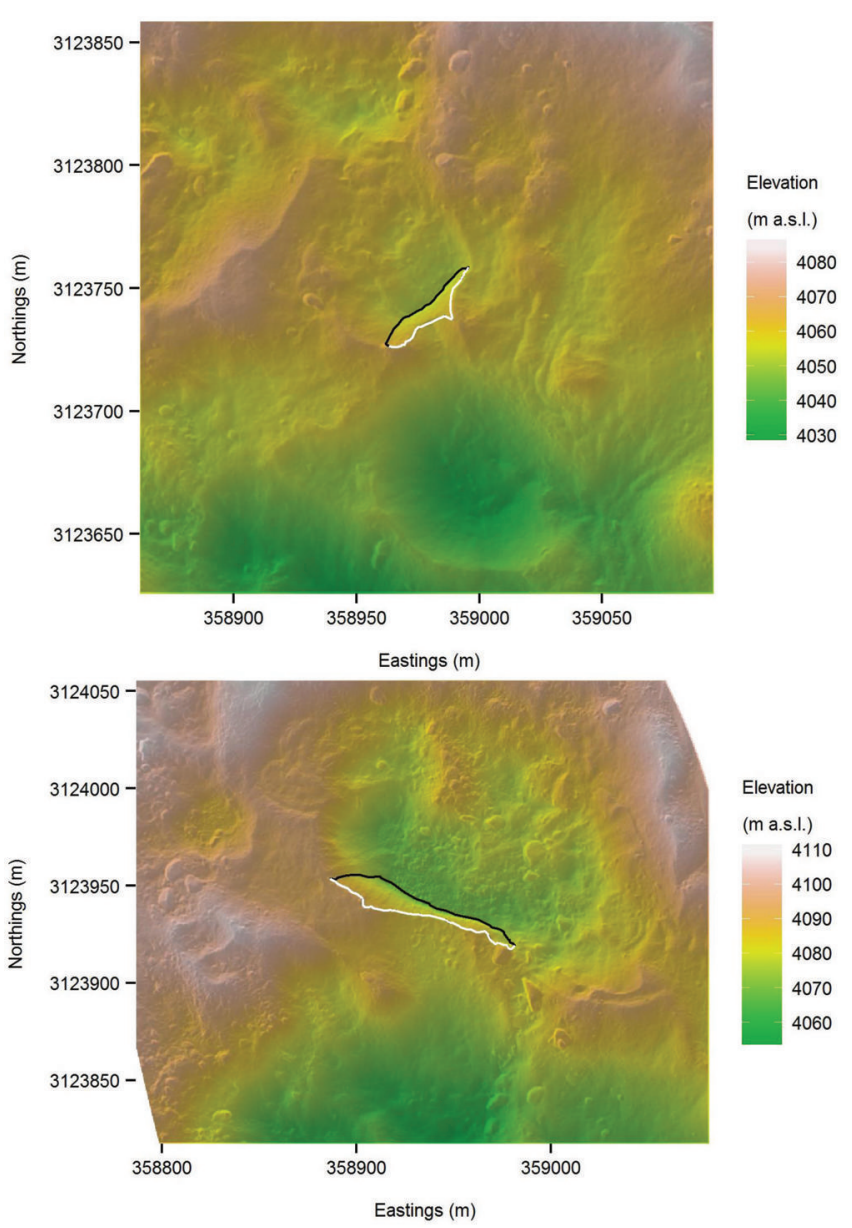

Fig. 3. UAV-DEMs ( $0.4 \mathrm{~m}$ resolution) showing the maximum area of influence for the calculations of longwave radiation for the entire cliff 1 (top) and cliff 2 (bottom). The area shown is such that it includes the $200 \mathrm{~m} \times 200 \mathrm{~m}$ area of interest for each of the cliff pixels. The two-dimensional shape of the cliffs is indicated by lines, with the white line marking the crest of the cliffs and the black line their bottom. The reference system of the map is WGS84 and the projection is UTM $45 \mathrm{~N}$.

of the glacier tongue and include cliffs 1 and 2 and their surroundings (Fig. 3). The 18 May UAV-DEM is used to prescribe the initial geometry of the cliffs. The highresolution orthophotographs $(0.1 \mathrm{~m})$ were used to delineate the outlines of the cliffs.

For calculation of shortwave and longwave radiative fluxes and their interaction with the nearby topography and more distant mountain ridges we used a combination of the high-resolution UAV-DEM and the ASTER-GDEM2 (Advanced Spaceborne Thermal Emission and Reflection Radiometer global DEM 2) with a resolution of 1 arcsec ( 30 m) (Tachikawa and others, 2011).

\subsection{Cliff ablation and surface topography}

Bamboo stakes were drilled across the ice surfaces of both cliffs, seven in May (three on cliff 1, four on cliff 2) and eight in October 2013 (five on cliff 1 and three on cliff 2) to record cliff melt (Fig. 1). Surface backwasting was measured during the two field trips (May and October). Surface albedo, slope and aspect were also measured at each stake, once in May and once in October 2013. Details of the stake measurements are given by Steiner and others (2015). Slope and aspect for every gridcell of $0.2 \mathrm{~m}$ resolution were calculated 


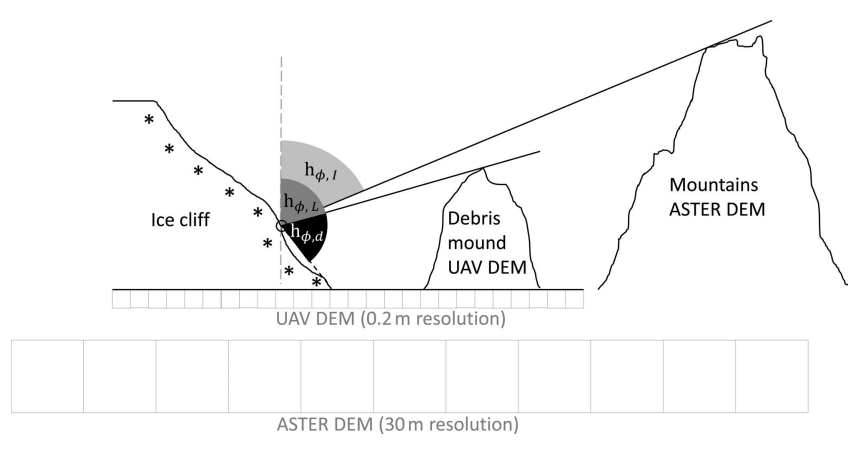

Fig. 4. Calculation of the individual horizon angles, $h_{\phi, l}$ (light grey) and $h_{\phi, \mathrm{L}}$ (dark grey), for shortwave and longwave radiation, respectively, and of the debris-view angle, $h_{\phi, \mathrm{d}}$ (black), for a single azimuth direction. The horizon angles are normalized either by $90^{\circ}$ $\left(h_{\phi, \mathrm{I}}\right.$ and $\left.h_{\phi, \mathrm{L}}\right)$ or by $180^{\circ}\left(h_{\phi, \mathrm{d}}\right)$ and then summed and divided by $360^{\circ}$, to determine a single sky-view factor for shortwave and longwave radiation, $V_{\mathrm{s}, \mathrm{I}}$ and $V_{\mathrm{s}, \mathrm{L}}$, and a debris-view factor, $V_{\mathrm{d}}$ (all dimensionless) for each location on the cliff. The grid below the topography indicates which DEM resolution is used for each individual angle (note that the resolution grid is shown only qualitatively and is not to scale). Where a debris mound dominates the horizon of a point on the cliff, $h_{\phi, \mathrm{l}}=h_{\phi, \mathrm{L}}$.

from the UAV-DEM. The mean slope of cliff 1 is $45.6^{\circ}$ and of cliff 2 is $53.2^{\circ}$, with standard deviations of $13.8^{\circ}$ and $15.1^{\circ}$, respectively (Table 1 ).

\section{MODEL}

The model used in this study is based on the point model of Steiner and others (2015), which itself built on simpler approaches proposed by Han and others (2010) and Reid and Brock (2014). The point model was coded into a distributed model that calculates each energy flux for every gridcell of a spatial domain describing the cliffs and their surroundings. The model was run for the period of measurements at AWS Lirung, from May to October 2013 (Section 3.1).

The energy balance at the cliff surface is

$$
Q_{\mathrm{m}}=I_{\mathrm{n}}+L_{\mathrm{n}}+H+\mathrm{LE}
$$

where $Q_{\mathrm{m}}$ is the energy flux available for melt, $I_{\mathrm{n}}$ and $L_{\mathrm{n}}$ are the net shortwave and longwave radiation fluxes, $H$ is sensible heat and LE is latent heat flux. All fluxes are perpendicular to the surface and in $\mathrm{W} \mathrm{m}^{-2}$. The heat from precipitation and conductive heat flux into the ice are neglected (Reid and Brock, 2014). Fluxes are assumed positive when they are directed towards the surface.

Ablation normal to the ice surface (m w.e.) was computed as

$$
M=\frac{Q_{\mathrm{m}} \Delta t}{\rho_{\mathrm{i}} L_{\mathrm{f}}}
$$

where $\Delta t$ is the time-step (here $3600 \mathrm{~s}$ ), $\rho_{\mathrm{i}}$ the ice density $\left(900 \mathrm{~kg} \mathrm{~m}^{-3}\right)$ and $L_{\mathrm{f}}$ the latent heat of fusion of ice $\left(334 \mathrm{~kJ} \mathrm{~kg}^{-1}\right)$.

\subsection{Sky- and debris-view factors}

The outlines of the two cliffs were derived from the orthophotographs and superimposed over the May UAVDEM to determine the initial geometry of the cliff. The elevation, slope and aspect for each gridcell were derived from the UAV-DEM. For every gridcell, a subsection of the
UAV-DEM of $200 \mathrm{~m} \times 200 \mathrm{~m}$ was used to represent the nearby topography (Fig. 3), and overlaid on the coarser ASTER-GDEM2 for calculations of the effect of more distant topography. The dimension of the UAV-DEM subsection was chosen based on tests with different extents, which showed that the debris mounds relevant for the cliff were represented relatively well from sub-areas of size $200 \mathrm{~m} \times 200 \mathrm{~m}$ or greater. Since the size of the sub-area is restricted by computational resources we decided to use $200 \mathrm{~m}$. From the two DEMs, the topographic and solar parameters needed for calculation of the radiative fluxes were determined. The horizon angle used for calculation of the shortwave radiation, $h_{\phi, l}$, defines the angle between the zenith and the horizon, for which the sky is visible, as a function of azimuth, $\phi$ (Fig. 4). The highest obstacle for each $\phi$ for both DEMs was taken, either from the UAV or from the coarser ASTER-DEM. Together, $h_{\phi, l}$ for the current solar azimuth and the solar elevation angle, $\theta$, define whether a gridcell receives direct sunlight at any given time (Section 4.2). The sky-view factor for the solar radiation, $V_{\mathrm{s}, \mathrm{l}}$, is the mean of all azimuths of $h_{\phi, 1}$ divided by $90^{\circ}$, representing the sky fraction which can be seen from a specific point.

The horizon angles used for calculation of the incoming longwave radiation, $h_{\phi, \mathrm{L}}$, were calculated from the UAVDEM (Section 4.3), and therefore the corresponding skyview factor, $V_{s, L}$, represents a local sky percentage. A debrisview factor, $V_{\mathrm{d}}$, was determined from the debris portion angle, $h_{\phi, d}$, using the UAV-DEM. $h_{\phi, d}$ describes the angular sector of debris seen from a point on the cliff and is limited by the local horizon line (at the top, $h_{\phi, \mathrm{L}}$ ) and the ice of the cliff (at the bottom; Fig. 4). $V_{\mathrm{s}, \mathrm{L}}$ and $V_{\mathrm{d}}$ were used to calculate the longwave radiative flux emitted by the sky and terrain, respectively (Section 4.3). The sky- and debris-view factors are constant in time, as long as the topography is assumed to be stable.

\subsection{Shortwave radiation flux}

The net solar radiation, $I_{n}$, for a unit area on an ice cliff with a given slope and aspect was calculated as

$$
I_{\mathrm{n}}=\left(I_{\mathrm{s}}+D_{\mathrm{s}}+D_{\mathrm{t}}\right)\left(1-\alpha_{\mathrm{i}}\right)
$$

where $I_{\mathrm{s}}$ is direct solar radiation, $D_{\mathrm{s}}$ is diffuse irradiance from the sky and $D_{\mathrm{t}}$ is incoming radiation reflected from the terrain (all fluxes in $\mathrm{W} \mathrm{m}^{-2}$ ). $\alpha_{\mathrm{i}}$ (dimensionless) is the albedo of ice.

Incoming shortwave radiation observed at AWS Lirung, $I_{0}$, was separated into direct and diffuse components, following Reindl and others (1990). The direct portion was then converted into the flux incident on a sloped unit area, as described by Han and others (2010), using the approach of Ohmura (1968), which requires calculation of the normal vector to the cliff surface and of the solar azimuth. This results in a reduction or enhancement of the direct component measured at AWS Lirung, depending on the angle between the two vectors. Calculations were made for each gridcell. Shading was calculated by comparing the position of the sun at each time-step to the corresponding $h_{\phi, 1}$.

Diffuse shortwave radiation from the sky was calculated as

$$
D_{\mathrm{s}}=V_{\mathrm{s}, \mathrm{l}} k_{\mathrm{d}} I_{0}
$$

where $k_{\mathrm{d}}$ (dimensionless) is the diffuse fraction according to Reindl and others (1990), depending on the clearness index, 
$k_{\mathrm{t}}$ (dimensionless), which is the ratio of $I_{0}$ to the theoretical extraterrestrial solar radiation, $l_{\mathrm{E}}\left(\mathrm{W} \mathrm{m}^{-2}\right) . k_{\mathrm{d}}$ was chosen according to the following relation:

$k_{\mathrm{d}}= \begin{cases}1.02-0.254 k_{\mathrm{t}}+0.0123 \sin \theta & k_{\mathrm{t}} \leq 0.3 \\ 1.4-1.749 k_{\mathrm{t}}+0.177 \sin \theta & 0.3<k_{\mathrm{t}} \leq 0.78 \\ 0.486 k_{\mathrm{t}}-0.182 \sin \theta & k_{\mathrm{t}}>0.78\end{cases}$

Diffuse radiation reflected by the terrain was calculated as

$$
D_{\mathrm{t}}=\alpha_{\mathrm{d}} I_{0}\left(1-V_{\mathrm{s}, 1}\right)
$$

where $\alpha_{\mathrm{d}}$ (dimensionless) is the albedo of the debris surface.

\subsection{Longwave radiation flux}

The net longwave radiation was calculated as

$$
L_{\mathrm{n}}=V_{\mathrm{s}, \mathrm{L}} L_{\text {in }}+V_{\mathrm{d}} L_{\mathrm{d}}-L_{\mathrm{o}}
$$

where $L_{\text {in }}$ is the incoming longwave radiation from the atmosphere for a horizontal, unobstructed location, $L_{d}$ is the longwave radiation emitted by the debris and $L_{0}$ is the outgoing longwave radiation emitted by the ice surface, all in $\mathrm{W} \mathrm{m}^{-2}$.

$L_{\text {in }}$ was modelled using the Stefan-Boltzmann relation as

$$
L_{\text {in }}=\epsilon_{\mathrm{s}} \sigma\left(T_{\mathrm{a}}+273.15\right)^{4}
$$

where $\sigma$ is the Stefan-Boltzmann constant and $\epsilon_{\mathrm{s}}$ (dimensionless) is the effective emissivity of the sky, estimated with the parameterizations of Dilley and O'Brien (1998) for clear sky and Unsworth and Monteith (1975) for cloudy conditions. This combination was found to give the best results in an evaluation of longwave radiation models (Juszak and Pellicciotti, 2013). The model was calibrated and validated for each season separately using data from an AWS in Kyanjing (3857 ma.s.I.), 2 km south of cliff 1 (Steiner and others, 2015).

The longwave radiation emitted by the surrounding debris was calculated as

$$
L_{\mathrm{d}}=\epsilon_{\mathrm{d}} \sigma\left(T_{\mathrm{s}}+273.15\right)^{4}
$$

where $\epsilon_{\mathrm{d}}$ (dimensionless) is the emissivity and $T_{\mathrm{s}}\left({ }^{\circ} \mathrm{C}\right)$ is the temperature of the debris, assumed to be equal to the surface temperature measured with a temperature logger (T-Logger) at the location of the AWS. Assumption of a spatially uniform surface temperature might be a limitation, but at present no adequate methods exist to model or spatially extrapolate surface temperature. In addition, Steiner and others (2015) showed that cliff ablation rates were only slightly sensitive to changes in surface temperature for the range of variability observed in the field at a number of T-Loggers. Those data also show that the temporal variability in surface temperature is much larger than its spatial variability, and the former is taken into account in the model, since the T-Logger provides a time series of hourly $T_{\mathrm{s}}$ values.

The outgoing longwave radiation was also calculated with the Stefan-Boltzmann relation, using the emissivity of ice, $\epsilon_{\mathrm{i}}$, and the ice surface temperature, $T_{\mathrm{i}}\left({ }^{\circ} \mathrm{C}\right)$, assumed to be equal to zero:

$$
L_{\mathrm{o}}=\epsilon_{\mathrm{i}} \sigma\left(T_{\mathrm{i}}+273.15\right)^{4}
$$

In Eqn (7), the sky- and debris-view factors, $V_{\mathrm{s}, \mathrm{L}}$ and $V_{\mathrm{d}}$, control the amount of longwave radiation from the atmosphere and the debris reaching each gridcell. $V_{\mathrm{s}, \mathrm{L}}$ is derived from the UAV-DEM (Section 4.1), using a domain of $200 \mathrm{~m}$. As a result, longwave radiation emitted by the terrain outside this domain is treated as longwave emitted by the atmosphere. This might result in some inaccuracy in the
Table 2. Optimized model parameters for May and October 2013 averaged across all stakes at cliff 1 and cliff 2, from Steiner and others (2015), and their mean values used for the distributed cliff model. $\alpha_{\mathrm{i}}$ and $\alpha_{\mathrm{d}}$ are albedo values for ice and debris, respectively, and $\epsilon_{\mathrm{i}}$ and $\epsilon_{\mathrm{d}}$ are the emissivities of the two surfaces. $z_{0}$, the surface roughness length, is in metres; all other variables are dimensionless

\begin{tabular}{lcccccc}
\hline & \multicolumn{3}{c}{ Cliff 1 } & & & Cliff 2 \\
Variable & May & October & Mean & May & October & Mean \\
& & & & & & \\
\hline$\alpha_{\mathrm{i}}$ & 0.278 & 0.273 & 0.275 & 0.057 & 0.214 & 0.136 \\
$\alpha_{\mathrm{d}}$ & 0.107 & 0.052 & 0.080 & 0.278 & 0.139 & 0.208 \\
$\epsilon_{\mathrm{i}}$ & 0.984 & 0.982 & 0.983 & 0.959 & 0.970 & 0.965 \\
$\epsilon_{\mathrm{d}}$ & 0.951 & 0.942 & 0.947 & 0.949 & 0.958 & 0.954 \\
$z_{0}$ & 0.004 & 0.003 & 0.003 & 0.003 & 0.003 & 0.003 \\
\hline
\end{tabular}

estimate of the longwave irradiance from the terrain (Plüss and Ohmura, 1997), but we assume this to be small.

\subsection{Turbulent fluxes}

The turbulent sensible, $H$, and latent heat, LE, fluxes were calculated as described by Steiner and others (2015), using the bulk aerodynamic method (Han and others, 2010; Reid and Brock, 2014). Aerodynamic surface roughness was estimated as described in Section 4.5.

\subsection{Optimal model parameters}

The following surface variables were not measured in the field: albedo of ice and debris, $\alpha_{\mathrm{i}}, \alpha_{\mathrm{d}}$; emissivities of ice and debris, $\epsilon_{\mathrm{i}}, \epsilon_{\mathrm{d}}$; and the surface roughness length, $z_{0}$. They can be regarded as model parameters and we took those of Steiner and others (2015), who used a Monte Carlo approach to optimize these parameters against measurements at ablation stakes. The parameters were optimized separately at each stake and for the pre-monsoon and postmonsoon seasons (Steiner and others, 2015) and we used the mean values calculated from all stakes on cliff 1 and all stakes in cliff 2, averaged over the two seasons (Table 2). Optimization of parameters across the entire cliff is impossible, as it would require a distributed dataset of accurate melt-rate series; instead we used an average of parameters rigorously calibrated at the single stake locations. We also averaged in time the parameters of Steiner and others (2015) (May and October), to avoid a sudden step change during the season and an arbitrary transition from the May to the October parameters. Use of average parameters in space and time is inevitable in distributed and continuous application of models.

A difference in ice albedo values between May and October can be observed at cliff 2 (Table 2). The lower ice albedo in May is likely explained by the generally warmer conditions of the pre-monsoon season, with higher melt and an increase in fine sediment transported down the cliff by the melting water and corresponding darkening of the ice surface. Post-monsoon, the air is colder and snow remained longer on the cliff surface, leading to a higher reflectance of shortwave radiation. The decrease of debris albedo from May to October is probably a result of the wetter surface, due to generally colder weather conditions, with less evaporation leading to a reduced or delayed drying-out of the surface during the day, in combination with shorter days. 

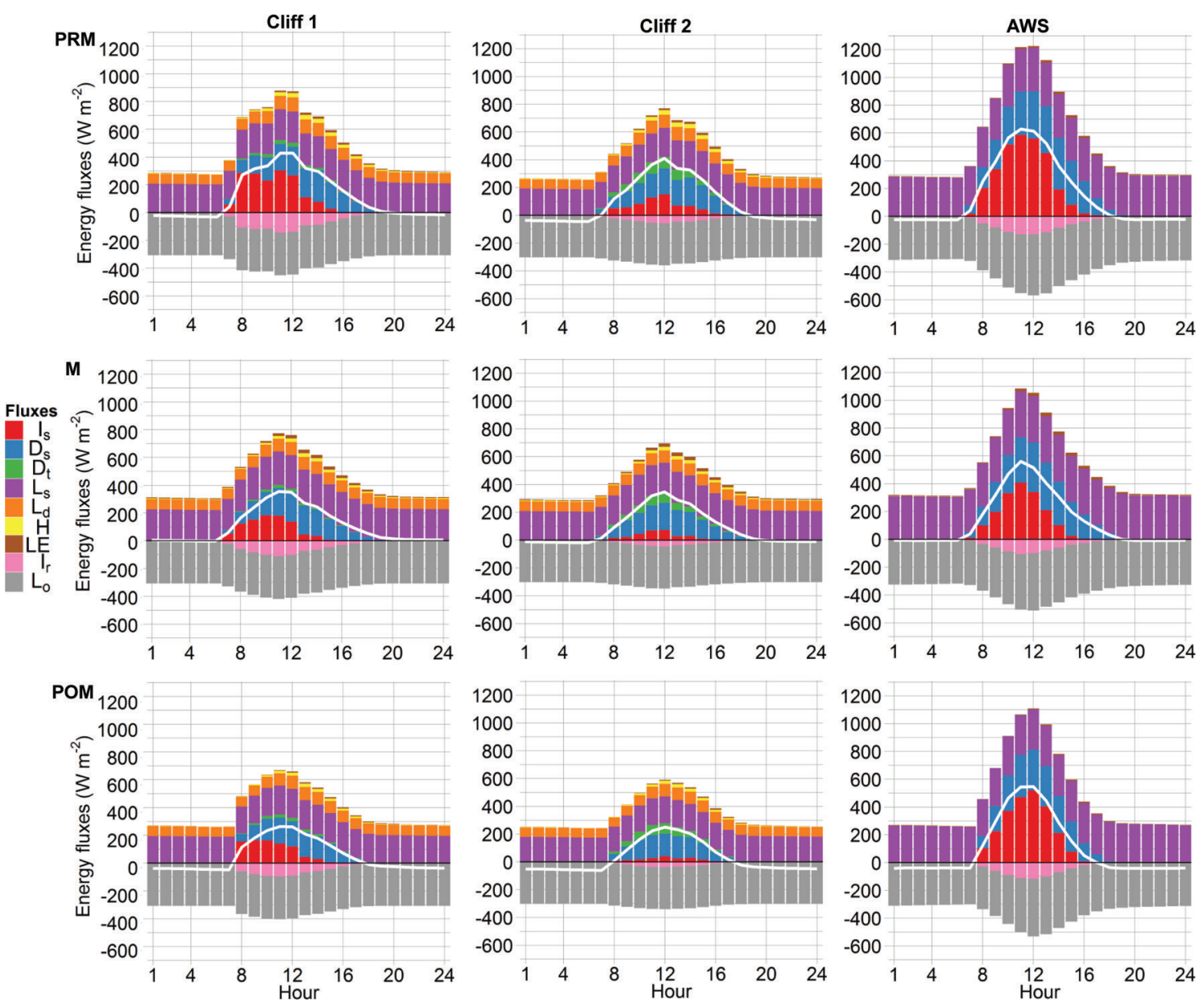

Fig. 5. Hourly energy fluxes averaged across each cliff for the three seasons separately (PRM: pre-monsoon; M: monsoon; POM: postmonsoon). For comparison the fluxes at a horizontal site (AWS) are also shown. Each hourly value is the mean of that hour over the season (in Nepal Time, UTC $+5: 45$ ). $I_{\mathrm{s}}$ is the direct incoming shortwave radiation, $D_{\mathrm{s}}$ and $D_{\mathrm{t}}$ are diffuse shortwave radiation from sky and from terrain, respectively. $I_{\mathrm{r}}$ is the reflected shortwave radiation, $L_{\mathrm{o}}$ the outgoing longwave radiation. $L_{\mathrm{s}}$ and $L_{\mathrm{d}}$ are incoming longwave radiation coming from sky and from debris, respectively. $H$ and LE are sensible and latent heat fluxes, respectively. The white curve represents $Q_{m}$.

\section{RESULTS AND DISCUSSION}

\subsection{Energy fluxes}

Figure 5 shows the mean hourly energy fluxes averaged across the cliff surface for each of the three subseasons. Incoming shortwave radiation has a strong diurnal cycle and is, in general, the highest flux during the day. But, in contrast to flat terrain, the diffuse component is very high, making up more than half of the total incoming flux at both cliffs. Diffuse radiation varies between $49 \%$ (cliff 1 , pre-monsoon) and $65 \%$ (cliff 2, monsoon) of the total flux (Table 3). It is highest during the monsoon (Table 3 ) because of cloudiness and is also high post-monsoon (58\% and 65\% at cliffs 1 and 2 , respectively) because of the low direct radiation in this season. Direct solar radiation is especially low at cliff 2 (Fig. 5), probably due to its steeper slope $\left(53.2^{\circ}\right.$ average slope compared with $45.6^{\circ}$ for cliff 1 ). This is a striking difference in comparison with flat or gently sloped surfaces, where the direct component makes up most of the total incoming flux. Radiation reflected by the terrain is quite small, given the low albedo of debris, but it is of some importance at cliff 2 (Fig. 5; Table 3).

The total incoming longwave radiation reaching the cliff is high during both day and night (Fig. 5), but is on average slightly lower than the outgoing flux (Table 3 ). When averaged over 24 hours it is higher than the total incoming shortwave flux in the monsoon and post-monsoon seasons (Table 3). Longwave radiation from the sky, $L_{s}=L_{\text {in }} V_{s, L}$, varies in the range $208-240 \mathrm{~W} \mathrm{~m}^{-2}$ at cliff 1 and $198-$ $229 \mathrm{~W} \mathrm{~m}^{-2}$ at cliff 2 (Table 3). It is slightly lower at cliff 2 (Table 3), probably because of its steeper slope, associated with a relatively high local horizon at the cliff crest. It is a lower flux than at AWS Lirung (with mean $L_{s} 229-265 \mathrm{~W} \mathrm{~m}^{-2}$ for all three seasons), because of the reduction of the visible sky at the two cliffs (the average sky-view factor for longwave radiation is 0.75 and 0.72 at cliffs 1 and 2, respectively, compared with 0.83 at AWS Lirung).

The reduced longwave radiation from the sky is balanced by the additional longwave radiation emitted by the debris. This flux would be very close to zero on a flat surface, but contributes $\sim 25 \%$ of the total incoming longwave radiation at both cliffs (Fig. 5; Table 3) and $\sim 15 \%$ of the total incoming short- and longwave radiation. The longwave radiation from the sky represents $73-75 \%$ at cliff 1 and $74-76 \%$ at cliff 2 of the total incoming longwave radiation for all three seasons (Table 3), but the spatial variability in the flux from the debris is considerably higher than that from the sky (Table 3). The net longwave radiation remains a negative flux, on average, at both cliffs, but of much smaller 
Table 3. Hourly mean, standard deviation, SD, and coefficient of variation, CV = SD/mean, of the energy fluxes, averaged spatially over the entire cliff, separated into pre-monsoon, monsoon and post-monsoon seasons. $I_{\text {in }}$ is incoming shortwave radiation (the sum of direct, $I_{\mathrm{s}}$, and diffuse radiation from the sky, $D_{\mathrm{s}}$, and from the terrain, $\left.D_{\mathrm{t}}\right) . I_{\mathrm{r}}$ is the reflected shortwave and $L_{\mathrm{o}}$ the outgoing longwave radiation. $L_{\text {in }}$ is incoming longwave radiation (the sum of longwave from sky, $L_{s}$, and from debris, $\left.L_{\mathrm{d}}\right) . H$ and LE are sensible and latent heat fluxes. Mean and $\mathrm{SD}$ are in $\mathrm{W} \mathrm{m}^{-2}, \mathrm{CV}$ is dimensionless. Also indicated are the mean energy available for melt, $Q_{\mathrm{m}}\left(\mathrm{W} \mathrm{m}^{-2}\right)$, and the mean melt rate, $M$ $\left(\mathrm{mm}\right.$ w.e. $\left.\mathrm{h}^{-1}\right)$. Statistics for shortwave components are calculated only for hours where mean $l_{\text {in }}$ was $>10 \mathrm{Wm} \mathrm{m}^{-2}$. The percentage contributions of the single components to $I_{\text {in }}$ and $L_{\text {in }}$ are indicated in parentheses. The mean daily sum of hourly melt rates is shown in parentheses $\left(\mathrm{mm}\right.$ w.e. $\mathrm{d}^{-1}$ ). Note that $\mathrm{CV}$ is not calculated for $Q_{\mathrm{m}}, \mathrm{H}$ or LE

\begin{tabular}{|c|c|c|c|c|c|c|c|c|c|c|}
\hline & & Pre-monsoon & & & Monsoon & & & Post-monsoon & & \\
\hline & Variable & Mean & SD & CV & Mean & SD & $\mathrm{CV}$ & Mean & $\mathrm{SD}$ & $\mathrm{CV}$ \\
\hline & $l_{\text {in }}$ & 299.5 & 70.0 & 0.234 & 222.7 & 38.6 & 0.173 & 229.7 & 51.0 & 0.222 \\
\hline & $I_{\mathrm{s}}$ & $139.3(46.5 \%)$ & 73.3 & 0.526 & $77.0(34.6 \%)$ & 41.4 & 0.538 & $84.6(36.8 \%)$ & 52.8 & 0.624 \\
\hline & $D_{\mathrm{s}}$ & $146.2(48.8 \%)$ & 5.6 & 0.038 & $135.3(60.7 \%)$ & 5.6 & 0.042 & $132.0(57.5 \%)$ & 4.4 & 0.034 \\
\hline & $D_{\mathrm{t}}$ & $14.0(4.7 \%)$ & 1.2 & 0.088 & $10.5(4.7 \%)$ & 1.0 & 0.092 & $13.1(5.7 \%)$ & 1.1 & 0.082 \\
\hline & $I_{\mathrm{r}}$ & 82.5 & 19.3 & 0.234 & 61.3 & 10.6 & 0.173 & 63.2 & 14.0 & 0.222 \\
\hline & $L_{\text {in }}$ & 303.6 & 3.6 & 0.012 & 320.1 & 2.4 & 0.007 & 285.0 & 2.9 & 0.010 \\
\hline Cliff 1 & $L_{\mathrm{S}}$ & $223.3(73.6 \%)$ & 0.8 & 0.004 & $240.3(75.1 \%)$ & 0.7 & 0.003 & $208.1(73.0 \%)$ & 0.7 & 0.003 \\
\hline & $L_{\mathrm{d}}$ & $80.3(26.4 \%)$ & 3.9 & 0.049 & $79.8(24.9 \%)$ & 2.6 & 0.032 & $76.9(27.0 \%)$ & 3.2 & 0.041 \\
\hline & $L_{0}$ & 310.3 & 0.0 & 0.000 & 310.3 & 0.0 & 0.000 & 310.3 & 0.0 & 0.000 \\
\hline & $H$ & 12.9 & 10.6 & & 10.7 & 7.0 & & 8.3 & 7.5 & \\
\hline & $L E$ & 7.4 & 5.4 & & 12.1 & 7.2 & & 3.8 & 3.6 & \\
\hline & $Q_{m}$ & 122.2 & 27.3 & & 113.5 & 8.4 & & 56.4 & 18.2 & \\
\hline & $M$ & $1.6(38.8)$ & 0.4 & 0.247 & $1.4(34.2)$ & 0.1 & 0.098 & 0.9 & 0.3 & 0.335 \\
\hline & $I_{\text {in }}$ & 256.8 & 53.7 & 0.209 & 193.5 & 31.0 & 0.160 & 189.4 & 35.4 & 0.187 \\
\hline & $I_{\mathrm{s}}$ & $79.6(31.0 \%)$ & 54.1 & 0.679 & $36.9(19.1 \%)$ & 30.9 & 0.837 & $28.2(14.9 \%)$ & 36.8 & 1.305 \\
\hline & $D_{\mathrm{s}}$ & $136.0(53.0 \%)$ & 7.6 & 0.056 & $125.9(65.0 \%)$ & 7.7 & 0.061 & $122.8(64.8 \%)$ & 6.1 & 0.049 \\
\hline & $D_{\mathrm{t}}$ & $41.2(16.0 \%)$ & 4.4 & 0.107 & $30.7(15.9 \%)$ & 3.5 & 0.113 & $38.4(20.3 \%)$ & 3.8 & 0.100 \\
\hline & $I_{\mathrm{r}}$ & 34.8 & 7.3 & 0.209 & 26.2 & 4.2 & 0.160 & 25.7 & 4.8 & 0.187 \\
\hline & $L_{\text {in }}$ & 285.8 & 3.6 & 0.013 & 301.6 & 2.4 & 0.008 & 268.3 & 3.0 & 0.011 \\
\hline Cliff 2 & $L_{\mathrm{s}}$ & $212.6(74.4 \%)$ & 1.0 & 0.005 & $228.8(75.9 \%)$ & 0.9 & 0.004 & $198.1(73.8 \%)$ & 0.9 & 0.004 \\
\hline & $L_{\mathrm{d}}$ & $73.3(25.6 \%)$ & 4.0 & 0.055 & $72.8(24.2 \%)$ & 2.6 & 0.036 & $70.2(26.2 \%)$ & 3.2 & 0.046 \\
\hline & $L_{0}$ & 304.5 & 0.0 & 0.000 & 304.5 & 0.0 & 0.000 & 304.5 & 0.0 & 0.000 \\
\hline & $H$ & 12.9 & 10.6 & & 10.7 & 7.0 & & 8.3 & 7.5 & \\
\hline & $L E$ & 7.4 & 5.4 & & 12.1 & 7.2 & & 3.8 & 3.6 & \\
\hline & $Q_{m}$ & 112.8 & 35.0 & & 103.7 & 17.7 & & 44.4 & 19.8 & \\
\hline & $M$ & $1.6(37.4)$ & 0.5 & 0.325 & $1.4(32.5)$ & 0.3 & 0.200 & $0.9(20.7)$ & 0.3 & 0.405 \\
\hline
\end{tabular}

magnitude than if the additional term from the debris were not present (Steiner and others, 2015).

The turbulent fluxes are both positive and small in magnitude at the two cliffs (Table 3 ), and both show an increase in the afternoon, associated with the differential increase between air and debris temperature that results in an increasing temperature deficit. One should notice, however, that these are the fluxes most affected by uncertainties in the spatial distribution of wind speed and surface roughness.

Turbulent fluxes are the same at both cliffs because air temperature and wind speed are assumed constant across the cliff and equal to those measured at AWS Lirung. All other fluxes differ between the two cliffs. The strongest difference between the two cliffs is in the average solar radiation, with cliff 1 receiving much more direct solar radiation, probably because it is less steep, while incoming longwave radiation is higher at cliff 1 , due to both higher radiation from the sky and higher flux from the surrounding terrain (Table 3).

The direct solar radiation flux has the strongest spatial variability (Table 3; Figs 6 and 7), showing coefficients of variation on the cliff of $53-62 \%$ for cliff 1 and $68-130 \%$ for cliff 2 (average values over each season) and much higher for individual hours. The flux is higher during the day (Figs 6 and 7), when it is also highly variable spatially, with radiation as high as $600 \mathrm{~W} \mathrm{~m}^{-2}$ in the upper section of cliff 2 (Fig. 7) and in the central part of cliff 1 (Fig. 6) and strongly reduced to almost zero in the steeper lower sections. On cliff 2, at 14:00 the entire surface is already in shade, while in the first part of the day the highest radiation is on the eastern part of the cliff (Fig. 7). On cliff 1, radiation is already high at 8:00, in contrast to cliff 2, which is mostly shaded at that time. On this cliff, a reduction due to shading is still evident on the eastern side around midday (e.g. at 11:00; Fig. 7).

The longwave radiation is less variable in space (Table 3 ), but the debris component has a strong local variability (Fig. 8).

\subsection{Melt}

As a result of the variability in radiative fluxes, melt is highly variable in space (Fig. 9), with variations between $10 \%$ (monsoon) and 33\% (post-monsoon) in daily melt at cliff 1 and between 20\% (monsoon) and 40\% (post-monsoon) at cliff 2. Daily melt is higher pre-monsoon, followed by the monsoon and post-monsoon seasons (Fig. 9). In all three seasons, melt is higher at the cliff top for both cliffs. Cliff 2 melts most in the middle section of its top (where slopes are shallower, results not shown), whereas at cliff 1 high melt rates are evident in the entire central section of the cliff almost down to its bottom (Fig. 9). The pattern on cliff 1 

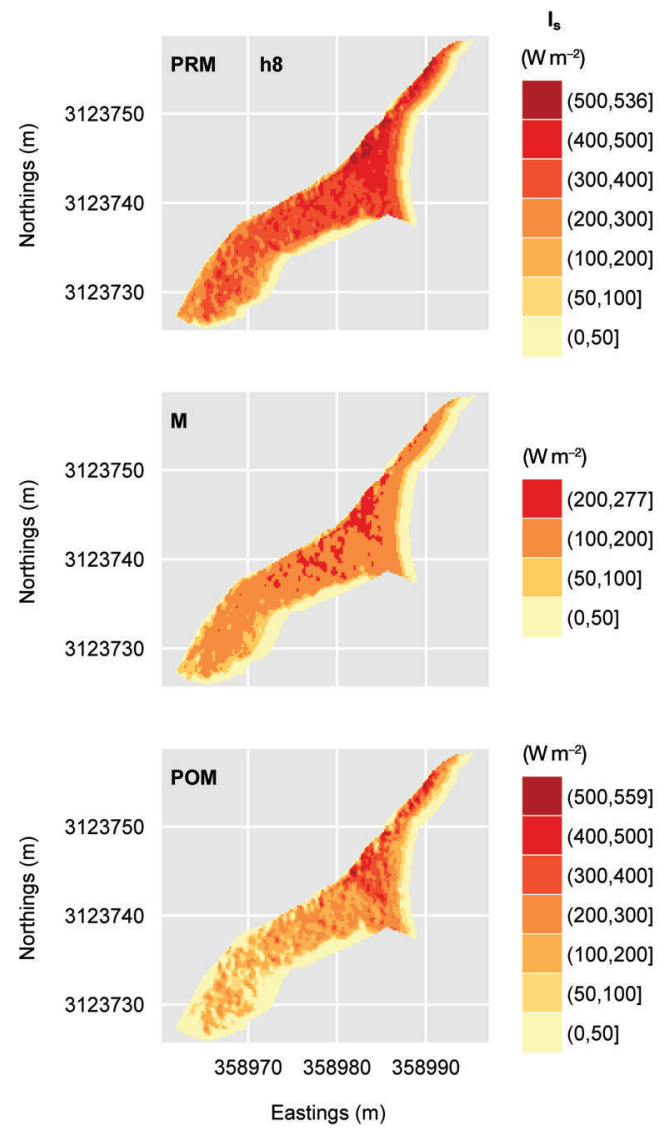

\section{$\left(\mathrm{W} \mathrm{m}^{-2}\right)$}

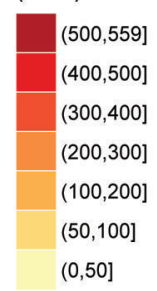

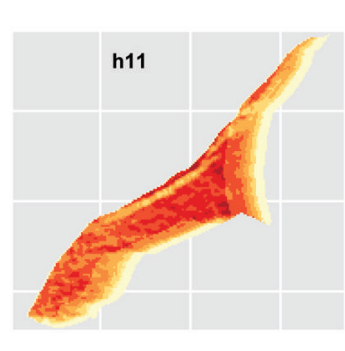
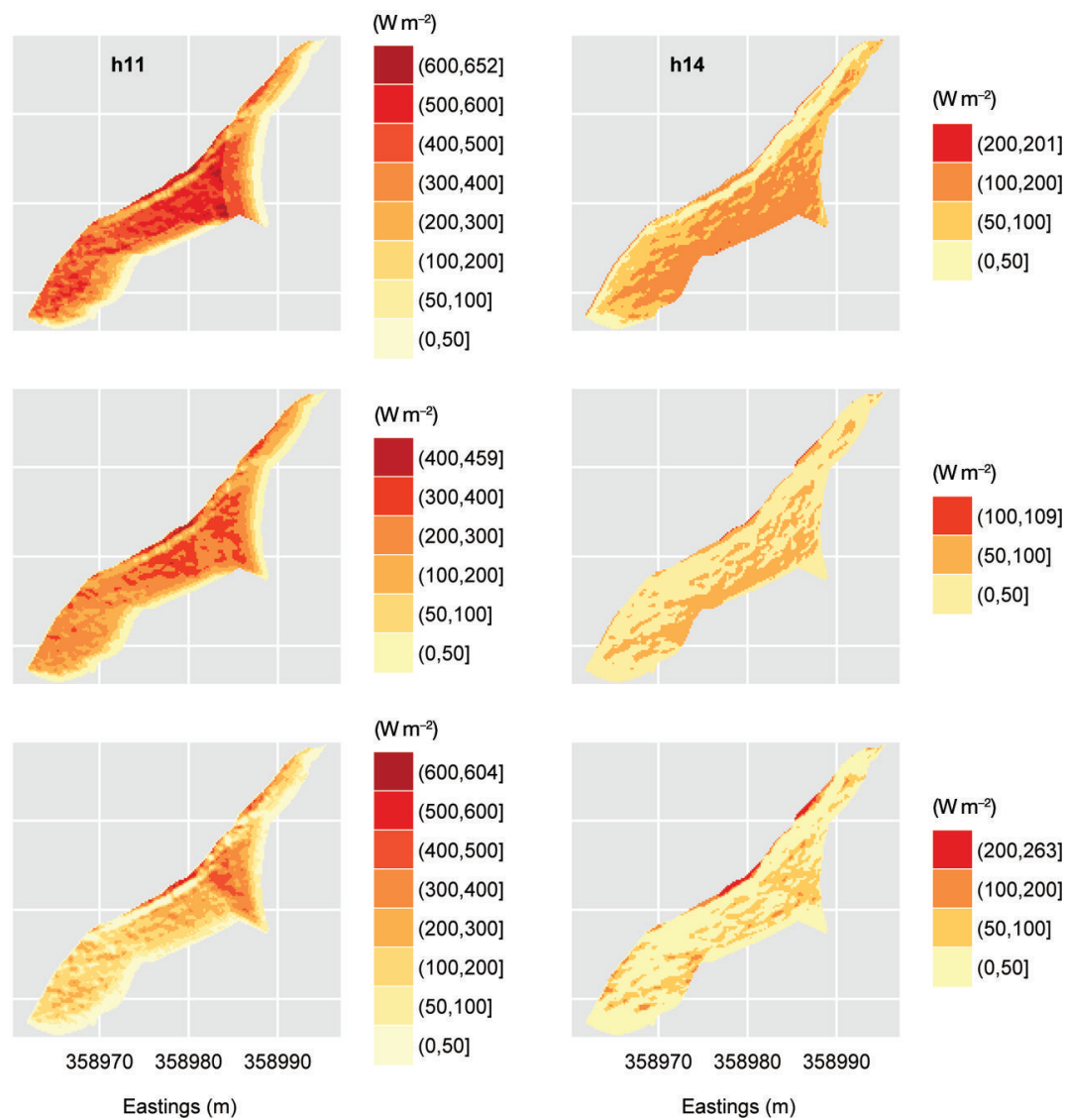

\section{$\left(\mathrm{Wm}^{-2}\right)$}

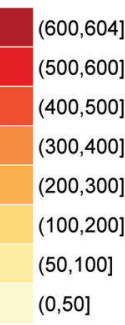

$(0,50]$

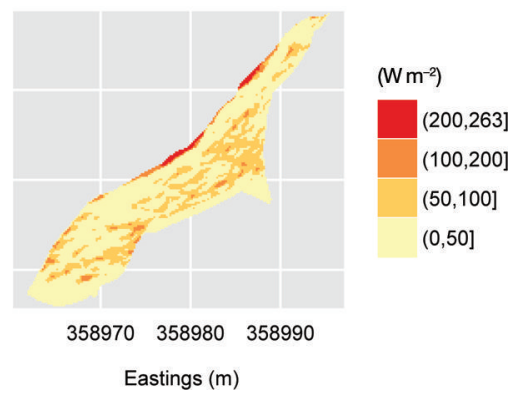

Fig. 6. Distribution of incoming direct shortwave radiation, $I_{\mathrm{s}}\left(\mathrm{W} \mathrm{m}^{-2}\right)$, at cliff 1 at 8:00, 11:00 and 14:00 (in Nepal Time, UTC $+5: 45$ ) in premonsoon (PRM), monsoon (M) and post-monsoon (POM) seasons. The reference system of the map is WGS84 and the projection is UTM $45 \mathrm{~N}$.

seems to be explained mostly by direct solar radiation, which is higher in the central section of the cliff during the morning hours in all three seasons, but especially premonsoon (Fig. 6). The high melt at the crest of the cliffs results from a combination of different fluxes. At cliff 2, high longwave radiation from the debris compensates the low direct solar radiation (Fig. 5), and both the diffuse shortwave radiation from the sky and the longwave from the sky are
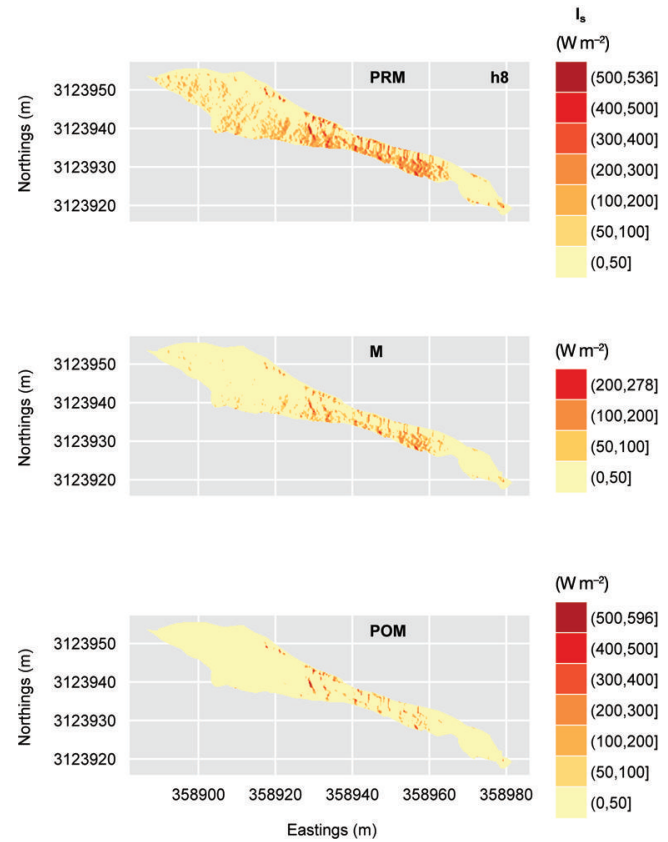
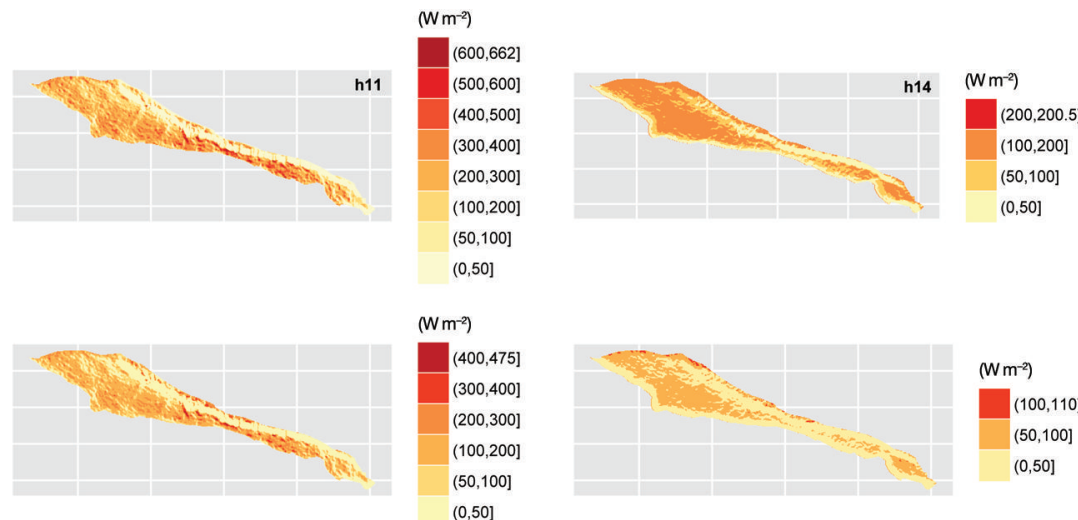

$\left(W m^{-2}\right)$

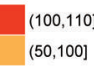
$(0,50]$
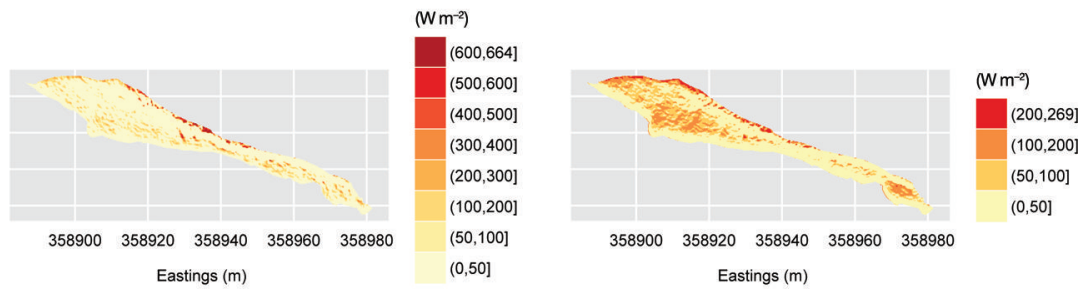

Fig. 7. Distribution of incoming direct shortwave radiation, $I_{\mathrm{s}}\left(\mathrm{W} \mathrm{m}^{-2}\right)$, at cliff 2 at 8:00, 11:00 and 14:00 (in Nepal Time, UTC $+5: 45$ ) in premonsoon (PRM), monsoon ( $\mathrm{M})$ and post-monsoon (POM) seasons. The reference system of the DEM is WGS84 and the projection is UTM $45 \mathrm{~N}$. 


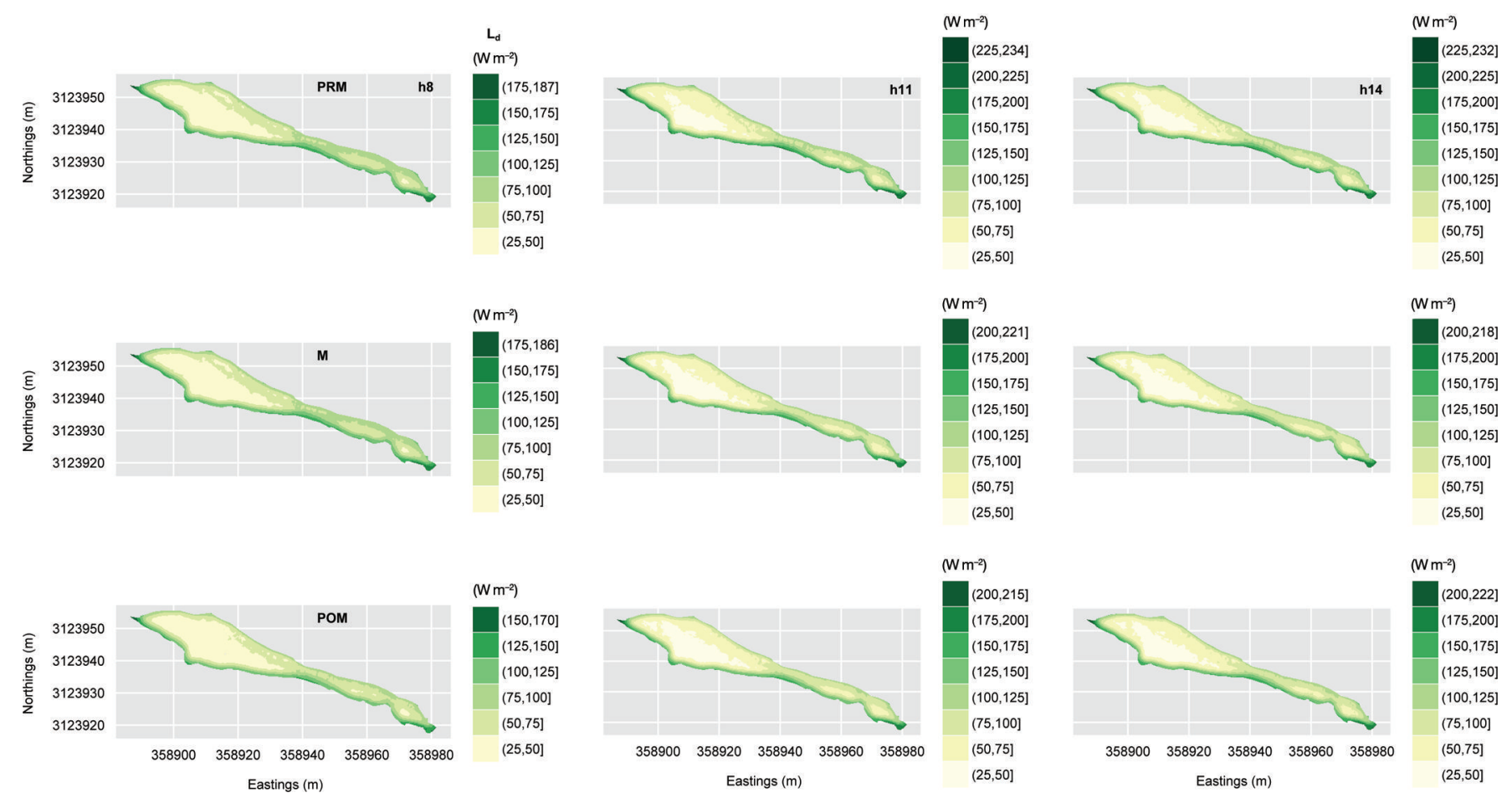

Fig. 8. Distribution of longwave radiation from debris, $L_{d}\left(\mathrm{~W} \mathrm{~m}^{-2}\right)$, at cliff 2 at 8:00, 11:00 and 14:00 (in Nepal Time, UTC $+5: 45$ ) in premonsoon (PRM), monsoon (M) and post-monsoon (POM) seasons. The reference system of the DEM is WGS84 and the projection is UTM $45 \mathrm{~N}$.
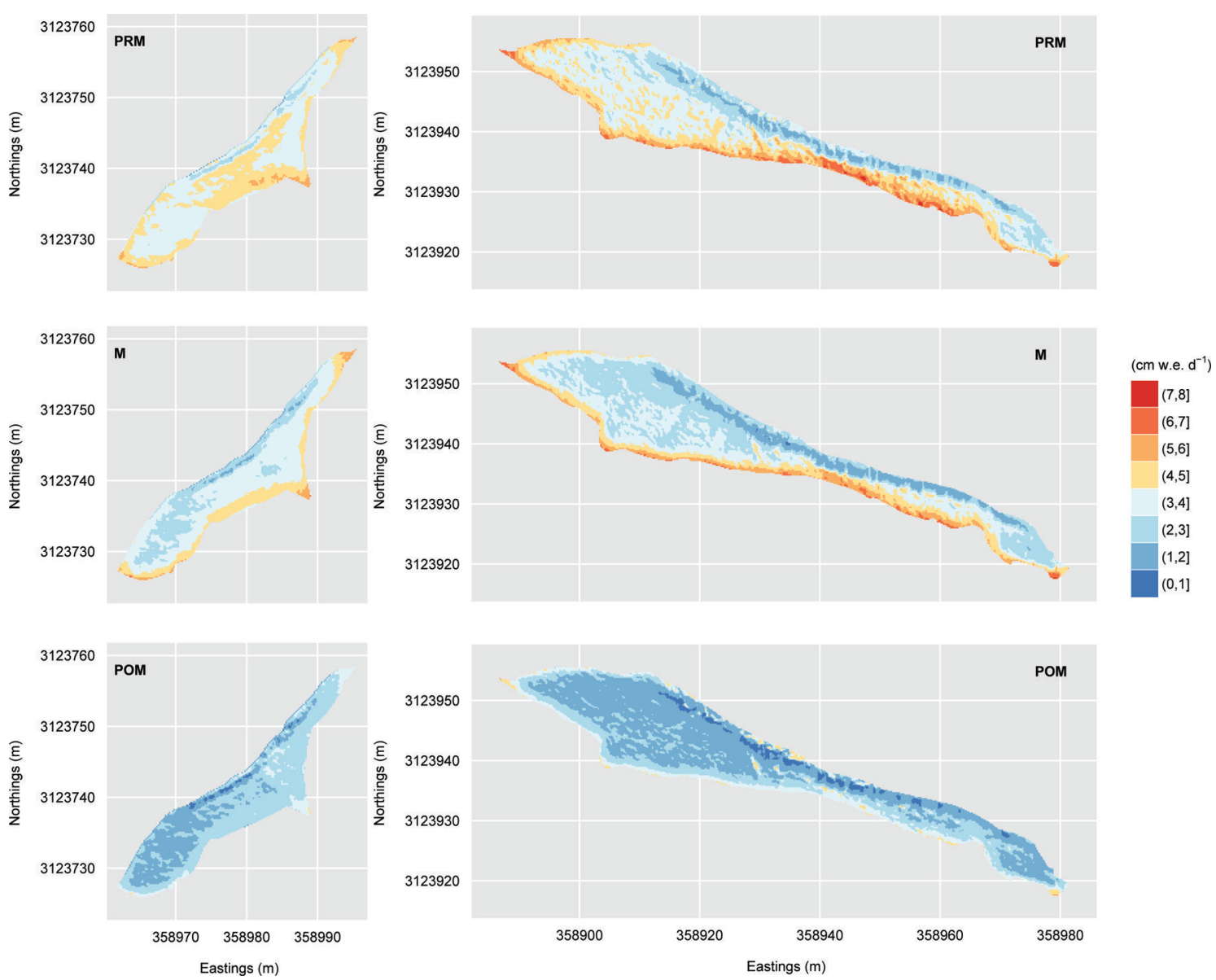

Fig. 9. Distribution of daily melt rate (cm w.e.) for cliff 1 (left) and cliff 2 (right) for pre-monsoon (PRM), monsoon (M) and post-monsoon (POM) periods. The reference system of the DEM is WGS84 and the projection is UTM 45N 


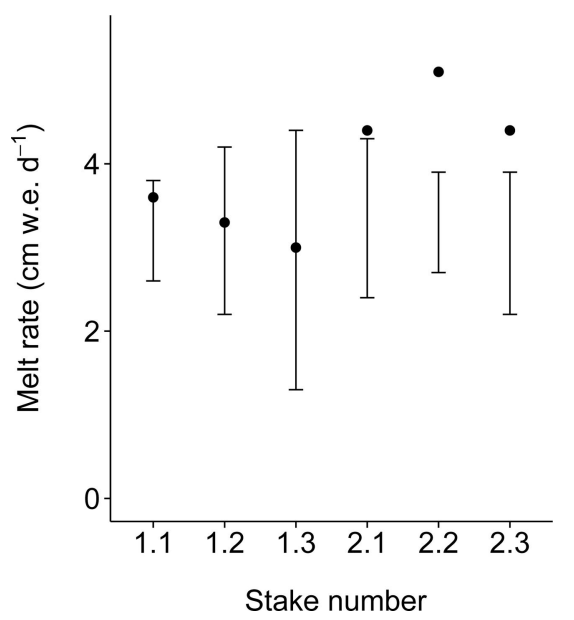

Fig. 10. Mean observed daily melt rates $\left(\mathrm{cm}\right.$ w.e. $\left.\mathrm{d}^{-1}\right)$ (dots) at cliff 1 (stakes 1.1-1.3) and cliff 2 (stakes 2.1-2.3) from 8 to 20 May 2013 (12 days) and range of modelled values (bars) within $1.5 \mathrm{~m}$ radius.

high along the crest. On cliff 2, direct shortwave radiation is very high in the middle of the crest (Fig. 7), and adds to the longwave radiative flux from the debris which is high along the cliff top (Fig. 8). This flux is very high at both cliffs along their edges, both on the top and bottom of the cliff. This explains the fact that on both cliffs, but especially on cliff 2, melt rates are also high along the western bottom part of the cliffs (Fig. 9), probably due to a combination of reduced shading, evident for cliff 1 (Fig. 6), and high longwave radiation from the debris (at both cliffs). Melt rates on the steeper, lower parts of the cliffs are lower, and due mostly to the longwave radiation emitted by the debris and the shortwave radiation reflected by the terrain, which, unlike all other fluxes, has a maximum at the cliff bottoms.

Spatially averaged daily melt on the cliff is slightly higher at cliff 1 , with values between $2.3 \mathrm{~cm}$ w.e. $\mathrm{d}^{-1}$ (postmonsoon) and $3.9 \mathrm{~cm}$ w.e. $\mathrm{d}^{-1}$ (pre-monsoon), than at cliff 2, with mean melt rates between $2.1 \mathrm{~cm}$ w.e. $\mathrm{d}^{-1}$ (postmonsoon) and $3.7 \mathrm{~cm}$ w.e. $\mathrm{d}^{-1}$ (pre-monsoon; Table 3). However, cliff 2 shows a wider range of melt per day in all three seasons $\left(1.1-7.8,0.8-7.1\right.$ and $0.5-5.3 \mathrm{~cm}$ w.e. $\mathrm{d}^{-1}$ in the pre-monsoon, monsoon and post-monsoon seasons, respectively) than cliff $1(1.7-5.7,1.4-6.1$ and $0.5-$ $4.2 \mathrm{~cm}$ w.e. $\mathrm{d}^{-1}$ for pre-monsoon, monsoon and postmonsoon, respectively).

Although the horizontally projected areas of the cliffs only represent $0.02 \%$ (cliff 1 ) and $0.07 \%$ (cliff 2) of the debris-covered area, they contribute $\sim 0.27 \%$ (cliff 1 ) and $0.96 \%$ (cliff 2) of the total meltwater estimated for the debris-covered part of Lirung Glacier using a physically oriented glacio-hydrological model (Ragettli and others, 2015). The total volume lost to melt by the two cliffs is 2313 and $8282 \mathrm{~m}^{3}$ for cliffs 1 and 2, respectively, for the entire measurement period. The much larger loss of volume of cliff 2 is mainly due to its larger surface $\left(1786 \mathrm{~m}^{2}\right.$, compared with $431 \mathrm{~m}^{2}$ for cliff 1 ).

Earlier studies have estimated the contribution of cliffs on different glaciers to the total ablation of the debris-covered area as $18 \%$ (Sakai and others, 2002), 7.3\% (Han and others, 2010) and 7.4\% (Reid and Brock, 2014). (We exclude the extremely high estimate of $69 \%$ reported by Sakai and others, 1998.) These estimates depend not only on the estimated total melt at the cliffs, but also on the total melt from the glacier, which might be problematic to calculate given the large uncertainties in debris thickness and meteorological forcing (e.g. Reid and Brock, 2014). Reid and Brock (2014) calculated total melt from the debriscovered area of Miage glacier using an energy-balance model with a constant debris thickness, while Han and others (2010) extrapolated an order-of-magnitude estimate of the total meltwater from point mass-balance measurements. Total melt from the debris-covered portion of Lirung Glacier was estimated by Sakai and others (2002) from the simulations of Rana (1997) using a degree-day model forced with input data at Kathmandu.

In our study we have calculated total melt from only two of the cliffs observed on Lirung Glacier in 2013. We therefore derive an estimate of how much melt per unit area of cliff surface (horizontally projected) can be expected compared with a unit area of non-cliff debris-covered glacier surface, by dividing the relative melt volume contributed by the two cliffs by the relative area of cliffs (relative compared with the total ablation volume and area). This represents an index of how effective cliffs are, per unit area, at producing melt, which we can use to compare the contribution of cliff surfaces to total ablation. In this study, we find melt from ice cliffs is 13.7 times higher than from debris, compared with values of 5.7 and 9 times higher found by Reid and Brock (2014) and Sakai and others (2002), respectively. The difference in these ratios could be due to the different methods used to compute the glacierwide ablation in each of these studies, to the different climate conditions and different debris thickness. However, it might also suggest a tendency to underestimate cliff melt when using simple extrapolation.

Validation with the observed melt rates at different points on cliffs 1 and 2 from 8 to 20 May 2013 (12 days) is problematic, as the stake location has to be chosen visually from the orthophotograph and assigned to a corresponding cell of the DEM. As the spatial variability of topography and melt is high, a small error of a few tens of centimetres in locating the stake might result in large differences in slope and aspect. We therefore compare measured and modelled melt within a radius of $1.5 \mathrm{~m}$ around each assumed stake position. Comparison is good for cliff 1 (Fig. 10), for which the slopes and aspects derived from the DEM (and used in the model) and measured in the field are generally very similar (Table 4), apart from the slope at stake 1.3, which is close to an edge where the cliff changes its slope abruptly and distinctly (Fig. 1d). At cliff 2, the model underestimates observations (Fig. 10). Slopes and aspects measured in the field at the location of the stakes on cliff 2, however, differ considerably from those derived from the UAV-DEM used in the model, especially for the aspect (Table 4). Thus, the disagreement between model and observations might be attributed to differences in topographic parameters, as the model simulates ablation for surface conditions different from those where ablation was measured. The discrepancies between measured and DEM-derived slopes and aspects can be attributed to the presence on cliff 2 of pronounced longitudinal bulges and grooves. These features are significantly more marked than on cliff 1 , and can cause strong local differences in topographic parameters, which might not be seen by the DEM due to their small cross section, or which might be averaged out at the grid resolution.

An additional validation is provided by comparing the total melt volume calculated by the model with estimates of 
volume loss from subtraction of the two DEMs of May and October. Some caution has to be used here, since the calculation of the total volume lost by subtraction of the two DEMs is affected by uncertainties, and by glacier movement in particular. Glacier velocities were estimated to be negligible at cliff 1 (Immerzeel and others, 2014), while at cliff 2 a surface displacement of $\sim 1.5 \mathrm{~m}$ over the observed period was derived. We correct for the velocities at cliff 2 in a simple manner, to obtain a first order-of-magnitude estimate of the volume loss, by multiplying the surface movement by the estimated vertical and horizontal extents of the cliff. We obtain volume losses of 2402 and $8453 \mathrm{~m}^{3}$, which are very similar to those calculated with the distributed cliff model $(3.8 \%$ and $2.1 \%$ higher for cliffs 1 and 2, respectively).

While more sophisticated methods should be used for this validation, this first attempt, albeit affected by uncertainties, suggests that our model estimates are in the range of plausible values.

\subsection{Model strengths, limitations and outlook}

The model proposed in this paper is the first fully distributed, grid-based model of ice cliff ablation proposed in the literature, even though the point model of Reid and Brock (2014) was also applied to all the pixels identified as cliffs from the DEM of Miage glacier. The analysis of the variability of the energy fluxes and resulting ablation across a cliff is the first of its type, and has shown large spatial variations in all fluxes, with melt rates resulting from a combination of those spatial patterns. The melt rates obtained are higher near the cliff crests for both cliffs. They are also high at the cliff/debris margin on the western flanks (for both cliffs), because of the debris effect through emission of longwave radiation, and in the central part of the smaller cliff 1.

These spatial patterns suggest that a relaxation of the cliff angle occurs. Comparison of the average slope angles obtained from the UAV-DEMs in May and October indicates a slight degree of flattening, with slopes decreasing from $45.6^{\circ}\left(53.2^{\circ}\right)$ pre-monsoon to $41.1^{\circ}\left(49.1^{\circ}\right)$ post-monsoon for cliff 1 (cliff 2). However, the observed lowering is small. The relaxation of the cliff angle, if not compensated by similar rates at the steep lower parts, would lead the cliff to degrade. This would imply that cliffs decay and then form again every melt season. This interpretation, however, should be regarded with some caution, since the model does not include an update of the cliff geometry. This seems an important next step in this line of research. Together with this, more work on understanding the evolution of cliffs, their formation and decay, should be carried out. We cannot exclude the hypothesis of a relaxation of the cliff's angle that seems to be implied by our maps of ablation. However, against this hypothesis is the fact that melt rates calculated with the model, and shown in Figure 9, are calculated perpendicular to the surface. Melt rates per unit horizontally projected area will therefore be greater at the steep cliff base than on the upper parts of the cliff.

More importantly, our model does not include the effect of lakes, which are often associated with cliffs. The lakes will be responsible for subaqueous melt rates that might add to the ablation rate of the steepest sections of the cliffs in contact with the lake water and thus favour the cliffs backwasting uniformly rather than degrading. Miles and others (2016) calculated subaqueous melt for cliff 2 for the
Table 4. Slope and aspect values $\left(^{\circ}\right)$ at stake locations in May 2013, measured manually on the ice surface (left) and derived from the UAV-DEM (right). In the stake column the stake identifiers are those used in May 2013. 'Point' indicates exact point values, where topographic components were measured or where the stakes were assumed to be. 'Buffer' indicates the mean value derived from all pixels in the UAV-DEM within a $1.5 \mathrm{~m}$ buffer around the assumed stake position. The standard deviation is shown in parentheses

\begin{tabular}{|c|c|c|c|c|c|c|}
\hline \multirow[b]{3}{*}{ Stake } & \multicolumn{2}{|c|}{ Measured } & \multicolumn{4}{|c|}{ Derived from UAV-DEM } \\
\hline & \multirow[b]{2}{*}{ Slope } & \multirow[b]{2}{*}{ Aspect } & \multicolumn{2}{|c|}{ Buffer } & \multicolumn{2}{|c|}{ Point } \\
\hline & & & Slope & Aspect & Slope & Aspect \\
\hline 1.1 & 40 & 350 & $44(7)$ & 344 & 51 & 336 \\
\hline 1.2 & 40 & 352 & $40(7)$ & 1 & 45 & 6 \\
\hline 1.3 & 40 & 330 & 55 (18) & 331 & 76 & 328 \\
\hline 2.1 & 43 & 346 & $42(9)$ & 31 & 43 & 30 \\
\hline 2.2 & 40 & 350 & $46(5)$ & 36 & 47 & 38 \\
\hline 2.3 & 51 & 345 & $55(6)$ & 27 & 58 & 21 \\
\hline
\end{tabular}

same season, and found a rate sufficient to match the horizontally projected rate on the cliff, thus tending to sustain the cliff/lake system. This might suggest that cliffs coupled with lakes do indeed persist during the melting season, while those without might degrade. This is a very interesting hypothesis that should be further investigated through a coupled cliff and lake model and extension of the analysis to a larger sample.

Despite the advances suggested here, the model can still be improved. One way is to include spatially variable input fields of surface temperature, which is assumed to be uniform in space in our calculations, due to the lack of an appropriate method to extrapolate or model surface temperature. Similarly, inclusion of spatially variable fields of ice albedo might improve model simulations, but, again, knowledge is too limited to allow a parameterization to be established. It seems important also to include the overhanging parts of cliffs, which are not represented in highresolution UAV-DEMs. For this, DEMs obtained from terrestrial photogrammetry or laser scanning could provide an alternative and increase the precision of the cliffs' representation, which is prone to large errors due to steep slopes (Fujita and others, 2008; Nuimura and others, 2012).

\section{CONCLUSIONS}

In this paper, we have presented the first distributed, gridbased model of ice cliff backwasting. The model includes a physically based model of longwave and shortwave radiative fluxes, that takes into account the interplay between the inclined cliff surface and the complex topography of the surrounding terrain, which affects the shading of shortwave radiation and the emittance of longwave radiation from sky and terrain. We developed the model using a comprehensive set of data collected on Lirung Glacier during the 2013 ablation season at two cliffs, including meteorological variables, melt at different locations across the cliffs, observations of cliff geometry and a high-resolution DEM obtained with a camera placed on a UAV. The model was forced with data from an on-glacier AWS located near the two cliffs. The model parameters not measured in the field (surface albedo, emissivity and surface roughness) had been optimized with a Monte Carlo approach in a previous paper 
at numerous locations on the two cliffs and here we use the average values.

We used the model to investigate the spatial patterns of energy fluxes and ablation on the two cliffs and quantify the total volume lost during one melt season, from May to October 2013. Our main conclusions are:

Shortwave radiation at both cliffs is an important component of the energy balance during the day, but mostly due to its diffuse component from the sky, which contributes $49-65 \%$ of the total incoming shortwave radiation. This is in contrast to flat or gently sloped areas, where the direct component is dominant. The net shortwave radiation varies greatly in space, largely due to the high spatial variability of direct shortwave receipts, which are in the range $53-62 \%$ on cliff 1 and $68-130 \%$ on cliff 2, depending on the season considered.

Incoming longwave radiation is the highest positive energy flux over the 24 hour cycle. Radiation from the sky is reduced compared with that at the gently sloping location of the AWS, because of the slope of the cliff and obstruction by surrounding debris mounds. However, this reduction is compensated by the longwave radiation emitted by the debris-covered terrain, which represents $\sim 25 \%$ of the total incoming longwave flux averaged across the cliff. Its spatial variability is smaller than that of the shortwave radiation, but still high locally.

Melt rates vary considerably in space on both cliffs, with coefficients of variation of $10-40 \%$ over the entire season. The total volumes lost to backwasting are $2313 \mathrm{~m}^{3}$ for cliff 1 and $8282 \mathrm{~m}^{3}$ for cliff 2, which are about $0.27 \%$ and $0.96 \%$ of the total melt from the debris-covered part of Lirung Glacier, estimated with a physically oriented, advanced glacio-hydrological model that calculates melt under debris as a function of debris thickness. These values are high, and confirm the assumed importance of cliffs as contributors to total mass loss of debris-covered glaciers.

The model quality might be further developed by improving calculations of the turbulent fluxes, which are affected by our limited knowledge of air temperature and wind variability at the cliffs. Here we have used measurements from the AWS and assumed they are constant across the cliffs. Spatially variable surface temperature and albedo fields would also be an advance beyond spatially uniform inputs to the models, but parameterizations of these variables are not yet available. Our next steps will be to use our model to evaluate cliff backwasting and evolution over a longer period of time and test hypotheses of cliff formation and decay.

\section{ACKNOWLEDGEMENTS}

We thank Martin Heynen, Tek Rai, Simon Wicki and Peter Hill for their support in the field. Without them, the cliff measurements would not have been possible. All the participants in the two field campaigns of May and October 2013 made this work possible and are gratefully acknowledged, as are the Nepali helpers who were a great support. We also thank Joe Shea and the International Centre for Integrated Mountain Development (ICIMOD) for administrative and logistical support in Kathmandu. This study is funded by the Swiss National Science Foundation (SNF) project UNCOMUN (Understanding Contrasts in High Mountain Hydrology in Asia) and fieldwork was partially supported by a United States Agency for International Development (USAID) High Mountain Glacier Watershed Programs Climber-Scientist Grant (CCRDCS0010). Finally, we acknowledge the thorough comments of Lindsey Nicholson and an anonymous reviewer, as well as of Scientific Editor Koji Fujita, which helped to improve the manuscript.

\section{REFERENCES}

Benn DI and 9 others (2012) Response of debris-covered glaciers in the Mount Everest region to recent warming, and implications for outburst flood hazards. Earth-Sci. Rev., 114(1-2), 156-174 (doi: 10.1016/j.earscirev.2012.03.008)

Bolch T and 11 others (2012) The state and fate of Himalayan glaciers. Science, 336(6079), 310-314 (doi: 10.1126/science. 1215828)

Dilley AC and O'Brien DM (1998) Estimating downward clear sky long-wave irradiance at the surface from screen temperature and precipitable water. Q. J. R. Meteorol. Soc., 124(549), 1391-1401 (doi: 10.1002/qj.49712454903)

Fujita K and Sakai A (2014) Modelling runoff from a Himalayan debris-covered glacier. Hydrol. Earth Syst. Sci. Discuss., 11(2), 2441-2482 (doi: 10.5194/hessd-11-2441-2014)

Fujita K, Suzuki R, Nuimura T and Sakai A (2008) Performance of ASTER and SRTM DEMs, and their potential for assessing glacial lakes in the Lunana region, Bhutan Himalaya. J. Glaciol., 54(185), 220-228 (doi: 10.3189/002214308784886162)

Fyffe CL and 6 others (2014) A distributed energy-balance melt model of an alpine debris-covered glacier. J. Glaciol., 60 (221), 587-602 (doi: 10.3189/2014jog13j148)

Gardelle J, Berthier E and Arnaud Y (2012) Slight mass gain of Karakoram glaciers in the early twenty-first century. Nature Geosci., 5(5), 322-325 (doi: 10.1038/ngeo1450)

Gardelle J, Berthier E, Arnaud Y and Kääb A (2013) Region-wide glacier mass balances over the Pamir-Karakoram-Himalaya during 1999-2011. Cryosphere, 7(4), 1263-1286 (doi: 10.5194/ tc-7-1263-2013)

Han H, Wang J, Wei J and Liu S (2010) Backwasting rate on debriscovered Koxkar glacier, Tuomuer mountain, China. J. Glaciol., 56(196), 287-296 (doi: 10.3189/002214310791968430)

Immerzeel WW and 6 others (2014) High-resolution monitoring of Himalayan glacier dynamics using unmanned aerial vehicles. Remote Sens. Environ., 150, 93-103 (doi: 10.1016/j.rse. 2014.04.025)

Juszak I and Pellicciotti F (2013) A comparison of parameterizations of incoming longwave radiation over melting glaciers: model robustness and seasonal variability. J. Geophys. Res. Atmos., 118(8), 3066-3084 (doi: 10.1002/jgrd.50277)

Kääb A, Berthier E, Nuth C, Gardelle J and Arnaud Y (2012) Contrasting patterns of early twenty-first-century glacier mass change in the Himalayas. Nature, 488(7412), 495-498 (doi: 10.1038/nature11324)

Miles ES, Willis I, Pellicciotti F, Steiner JF, Buri P and Arnold N (2016) Refined energy-balance modelling of a supraglacial pond, Langtang Khola, Nepal. Ann. Glaciol., 57(71), 29-40 (doi: 10.3189/2016AoG71A421)

Nuimura T, Fujita K, Yamaguchi S and Sharma RR (2012) Elevation changes of glaciers revealed by multitemporal digital elevation models calibrated by GPS survey in the Khumbu region, Nepal Himalaya, 1992-2008. J. Glaciol., 58(210), 648-656 (doi: 10.3189/2012jog11j061)

Ohmura A (1968) The computation of direct insolation on a slope. Climatol. Bull., 3, 42-53

Pellicciotti F, Stephan C, Miles ES, Herreid S, Immerzeel WW and Bolch T (2015) Mass-balance changes of the debris-covered 
glaciers in the Langtang Himal, Nepal, from 1974 to 1999. J. Glaciol., 61(226), 373-386 (doi: 10.3189/2015jog13j237)

Petersen L and Pellicciotti F (2011) Spatial and temporal variability of air temperature on a melting glacier: atmospheric controls, extrapolation methods and their effect on melt modeling, Juncal Norte glacier, Chile. J. Geophys. Res., 116(D23), D23109 (doi: 10.1029/2011jd015842)

Plüss C and Ohmura A (1997) Longwave radiation on snowcovered mountainous surfaces. J. Appl. Meteorol., 36(6), 818-824 (doi: 10.1175/1520-0450-36.6.818)

Ragettli S and 9 others (2015) Unravelling the hydrology of a Himalayan catchment through integration of high resolution in situ data and remote sensing with an advanced simulation model. Adv. Wat. Resour., 78, 94-111 (doi: 10.1016/j.advwatres. 2015.01.013)

Rana B (1997) Application of a conceptual precipitation-runoff model (HYCYMODEL) in a debris-covered glacierized basin in the Langtang Valley, Nepal Himalaya. Ann. Glaciol., 25, 226-231

Reid TD and Brock BW (2014) Assessing ice-cliff backwasting and its contribution to total ablation of debris-covered Miage glacier, Mont Blanc massif, Italy. J. Glaciol., 60(219), 3-13 (doi: 10.3189/2014jog13j045)

Reid TD, Carenzo M, Pellicciotti F and Brock BW (2012) Including debris cover effects in a distributed model of glacier ablation. J. Geophys. Res., 117(D18), D18105 (doi: 10.1029/ 2012jd017795)
Reindl DT, Beckman WA and Duffie JA (1990) Diffuse fraction correlations. Sol. Energy, 45(1), 1-7 (doi: 10.1016/0038-092x (90)90060-p)

Sakai A, Nakawo M and Fujita K (1998) Melt rate of ice cliffs on the Lirung glacier, Nepal Himalayas, 1996. Bull. Glacier Res., 16, $57-66$

Sakai A, Takeuchi N, Fujita K and Nakawo M (2000) Role of supraglacial ponds in the ablation process of a debris-covered glacier in the Nepal Himalayas. IAHS Publ. 265, 119-132

Sakai A, Nakawo M and Fujita K (2002) Distribution characteristics and energy balance of ice cliffs on debris-covered glaciers, Nepal Himalaya. Arct. Antarct. Alp. Res., 34, 12-19

Shiraiwa T and Yamada T (1992) Glacier inventory in the Langtang Valley, Nepal Himalayas. Low Temp. Sci. Ser. A, Data report, 50, 47-72

Steiner JF, Pellicciotti F, Buri P, Miles ES, Immerzeel WW and Reid TD (2015) Modeling ice-cliff backwasting on a debris-covered glacier in the Nepalese Himalaya. J. Glaciol., 61(229), 889-907 (doi: 10.3189/2015JoG14J194)

Tachikawa T, Hato M, Kaku M and Iwasaki A (2011) Characteristics of ASTER GDEM version 2. In 2011 International Geoscience and Remote Sensing Symposium. Institute of Electrical and Electronic Engineers, Piscataway, NJ (doi: 10.1109/igarss.2011.6050017)

Unsworth MH and Monteith JL (1975) Long-wave radiation at the ground I. Angular distribution of incoming radiation. Q. J. R. Meteorol. Soc., 101(427), 13-24 (doi: 10.1002/qj. 49710142703) 